\title{
Building ambidextrous organizations through intellectual capital: A proposal for a multilevel model
}

\author{
Susana Fernández-Pérez de la Lastra(iD, Natalia García-CarbonelliD, Fernando Martín-Alcázar(iD, \\ Gonzalo Sánchez-GardeyiD \\ University of Cádiz. (Spain)
}

susana.fernandez@uca.es,natalia.carbonell@uca.es,fernando.martin@uca.es, gonzalo.sanchez@uca.es

Received December, 2016

Accepted June, 2017

\section{Abstract}

Purpose: This paper proposes an alternative theoretical model to describe, from a multilevel perspective, the way in which ambidexterity is built across different organizational levels, through specific combinations of intellectual capital dimensions-human, social and organizational capital.

Design/methodology: In this study, main arguments from intellectual capital, strategic human resource management (SHRM) and multilevel literature are integrated. The intellectual capital literature provides our model with the input (human capital), mechanisms (social capital) and the infrastructure (organizational capital) required to create ambidextrous capabilities. The multilevel perspective reveals the context in which ambidexterity is reached, and the SHRM provide the model with the specific mechanisms (policies and practices) and conditions required by ambidexterity (HRM flexibility and horizontal fit).

Findings: Although the literature widely recognizes ambidexterity as a potential source of sustainable competitive advantage, the processes by which organizations complement exploration and exploitation activities still remain unclear. This study sheds some light on the 
analysis of these complex dynamics, explaining how ambidextrous capabilities can arise from different alternative combinations of human, social and organizational capital.

Originality/value: The paper expands the extant literature in the field, describing different paths to achieving organizational ambidexterity. The configurational approach adopted adds value to the proposed model, as it helps to explaining alternative synergistic mixes of ambidextrous intellectual capital at different organizational levels.

Keywords: Ambidexterity, Human capital leveraging, Multilevel perspective, Strategic human resource management, Social processes

Jel Codes: M12, M19

\section{Introduction}

The survival of organizations in today's complex markets requires a combination of both efficiency and innovative strategic capabilities. In this context, it will be easier for the so-called ambidextrous organizations, that is, those able to develop exploratory and exploitative activities simultaneously, to offer superior performance and build sustainable competitive advantages (Jansen, Simsek \& Cao, 2012). However, the generation of these types of capabilities entails extremely complex processes and mechanisms that demand deeper efforts from research (Kang \& Snell, 2009; Kostopoulos, Bozionelos \& Syrigos, 2015).

The intellectual capital literature provides us with interesting arguments about extending the process of adjustment between exploration and exploitation activities, focusing on organizational knowledge stocks (Subramaniam \& Youndt, 2005). Intellectual capital dimensions -human, social and organizational- represent distinct knowledge stocks at different organizational levels (Subramaniam \& Youndt, 2005) that can play different roles when creating ambidextrous capabilities (Kang \& Snell, 2009). The literature describes how these intellectual capital dimensions will complement each other across different organizational levels, leading to better organizational results (Yang \& Li, 2009). This paper starts from the theoretical premise that organizations are able to deploy exploration and exploitation processes in a concurrent manner, through the development of certain patterns of 'ambidextrous intellectual capital'. 
To obtain such ambidextrous behaviours, organizations require the implementation of specific HRM practices. Organizations need to be able to define different HRM subsystems that provide employees with the abilities, the motivation and the opportunity according to AMO Theory (Appelbaum, Bailey, Berg \& Kalleberg, 2000) to simultaneously perform exploration and exploitation activities (Lepak, Liao, Chung \& Harden, 2006). The creation of ambidextrous intellectual capital will be notably affected by the level of integration between different HRM subsystems (Kang \& Snell, 2009; Yang \& Li, 2009). In this sense, the HRM configurational approach has traditionally defended the need to ensure that different HRM practices are internally coherent and produces positive synergies (horizontal fit) (Delery, 1998). On the other hand, as Kozlowski and Klein (2000) asserted, "organizations do not 'perform', it is the individuals in an organization who perform in ways that allow the organizations to achieve desirable effectiveness and performance outcomes" (Lepak et al., 2006, pp. 230). Therefore, following this argument, we introduce intellectual capital multilevel foundations to explain the process whereby the human capital of individuals is transformed and leveraged (Ployhart \& Moliterno, 2011), to finally create ambidextrous intellectual capital within organizations (Gupta, Smith \& Shalley, 2006). The above-mentioned HRM systems will be a crucial tool in developing efficient leveraging processes.

Drawing on the intellectual capital, strategic human resource management (SHRM) and human capital literature, this paper proposes an integrative theoretical model offering a configurational explanation of how organizations generate ambidextrous intellectual capital. To do so, the study explores alternative configurations through which organizations can transform and leverage individual human capital to strategic levels, building ambidextrous competences at the organizational level.

\section{Ambidextrous intellectual capital: Some conceptual refinements}

Diverse studies have focused on intellectual capital arguments to explain how companies achieve ambidextrous behaviours through the combination and management of their dimensions-human, social and organizational capital (Kang \& Snell, 2009; Kang, Snell \& Swart, 2012). The conceptual dispersion and the lack of a clear definition of some of the basic constructs involved makes it difficult to fully understand these complex mechanisms and to appropriately integrate exploratory and exploitative requirements (Kang \& Snell, 2009; Kostopoulos et al., 2015). Considering this, we will start building our proposal by defining some of the basic concepts.

Generally, ambidexterity refers to the company's ability to simultaneously implement exploitative and explorative processes (Turner, Maylor \& Swart, 2015, pp. 177). Exploitation is related to taking 
advantage of the value of existing markets, resources and competences, by applying repetitive combinative processes on the basis of the organization's existing knowledge. In turn, exploration implies that companies are also able to explore new opportunities, markets and/or products, searching for unusual knowledge domains and applying new mechanisms and procedures (Kang \& Snell, 2009; Jansen et al., 2012). On the basis of this definition, and following Turner et al.'s (2015) synergistic combinations of human, social and organizational capital, different levels of ambidextrous capabilities can be explained. However, not all combinations would provide the organization with the highest level of ambidexterity, and may produce 'suboptimal' types of ambidexterity (Kang \& Snell, 2009). In this sense, to obtain sustainable competitive advantages from the ambidexterity, not just any type of intellectual capital is desirable. This idea leads us to explicitly redefine ambidextrous intellectual capital as the stock of knowledge and the capacity of innovation that organizations have to develop exploration and exploitation processes, building ambidexterity as a source of sustainable competitive advantages. Accordingly, we can conclude that it would be composed of three main facets: ambidextrous human capital, social and organizational capital.

Ambidextrous buman capital refers to the knowledge, skills, abilities and behaviours that allow individuals to implement exploratory and exploitative activities, the organizational implications of which are notably different from those related to traditional human capital. Drawing on Kang and Snell's (2009) human capital distinction between generalist and specialist profiles, and considering the different nature of exploration and exploitation activities, an alternative human capital classification can be proposed that has four typologies (Figure 1). As Figure 1 shows, typology IV, Generalist human capital, will involve those employees who possess high levels of both explorative and exploitative competences. These competences would lead them to efficiently combine both types of actions to perform (Kostopoulos et al., 2015). Indeed, the generalist human capital implies multi-skilled attitudes, a more flexible set of capabilities, wider experiences and more diverse mental models (i.e. rational and intuitive cognitive skills), thereby improving the individual's abilities to adapt, comprehend, interpret, discover and apply new knowledge (Shane, 2000). These individuals will be polyvalent, being capable of not only deploying exploration and exploitation, but also applying new knowledge in the future (Kang \& Snell, 2009). 


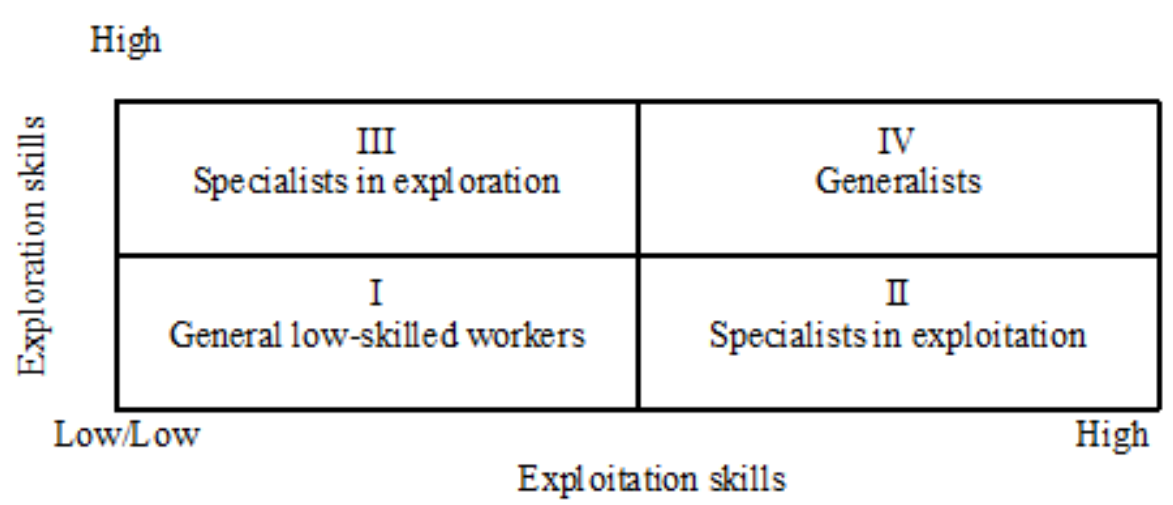

Figure 1. Human capital classification for exploration and/or exploitation activities

The activities of exploration and exploitation both require different behaviours so that distinct cognitive skills will also be demanded (Laureiro-Martínez, Brusoni, Canessa \& Zollo, 2015). Consequently, the combination of these attributes will lead individuals to have paradoxical cognitive frames, fostering those ambidextrous behaviours (Kostopoulos et al., 2015). In this vein, ambidexterity will manifest at the individual level by the achievement of virtuous circles rather than oppositional spirals, supporting the dynamic and complementary nature of these activities (Papachroni, Heracleous \& Paroutis, 2014). Therefore, from an individual level, generalist human capital profiles will include the knowledge, skills and abilities to show ambidextrous capabilities by definition.

However, generalists are not alone in having the potential to be ambidextrous. In fact, specialist profiles, if they are properly managed and synergistically integrated, can contribute to the generation of ambidextrous organizational capabilities (Kang \& Snell, 2009). In fact, to develop ambidexterity from the confluence of specialists, the proper ambidextrous social capital needs to be built. In this vein, social capital is understood as those patterns of internal and external relationships among employees and other agents, acting as a relevant mechanism for knowledge transfer and exchange (Kang \& Snell, 2009; Ployhart \& Moliterno, 2011). Implicit in the previous definition is that the most valuable knowledge usually resides in social networks and relationships (Nahapiet \& Ghoshal, 1998). It plays a crucial role in creating incremental and radical innovations and is inseparably linked to human capital. Therefore, the first step to creating relevant social capital would be to build the necessary individual interaction skills (Subramaniam \& Youndt, 2005).

Based on the dimensions of social capital (structural, affective and cognitive), Kang and Snell (2009) describe two opposite social systems, cooperative and entrepreneurial, which are directly linked to 
exploitation and exploration activities, respectively (Table 1). The former is characterized as a tight interaction system where social networks are strong and dense. Institutional trust exists and a common understanding on the way in which knowledge has to be integrated is clearly defined and accepted. These attributes facilitate efficient integration of habitual and well-developed knowledge. Nevertheless, for exploration actions, a more flexible social system is required. In that case, the entrepreneurial system offers weak and non-redundant networks with sporadic contacts; trust relies on personal and direct experiences derived from resilient dyadic contacts and there is a shared knowledge of operations and techniques. These attributes allow organizations to better learn, transmit, transfer and share new knowledge.

\begin{tabular}{|c|c|c|c|}
\hline \multirow{2}{*}{ Social systems } & \multicolumn{3}{|c|}{ Social capital dimensions } \\
\hline & Structural & Affective & Cognitive \\
\hline Cooperative & $\begin{array}{l}\text { Strong and dense } \\
\text { networks }\end{array}$ & Institutional trust & $\begin{array}{c}\text { Common understanding } \\
\text { of how knowledge is } \\
\text { integrated }\end{array}$ \\
\hline Entrepreneurial & $\begin{array}{l}\text { Weak and non-redundant } \\
\text { networks }\end{array}$ & Individual trust & $\begin{array}{l}\text { Shared technical and } \\
\text { operational knowledge }\end{array}$ \\
\hline
\end{tabular}

Table 1. Summary of social systems characteristics

Considering what we have just explained, we can conclude that ambidexterity appears because of factors other than just the presence of individual ambidextrous human capital. Different connections between specialists in exploration or exploitation, ambidextrous groups, or even specialist groups may be a potential source of ambidexterity. In such diverse situations, different ways of making contacts and interactions would support the creation of ambidexterity. Chart 2 depicts the theoretical classification of social systems needed for each combination of exploration-exploitation activities. Similar to previous ambidextrous human capital explanations, typology IV will show those social systems that are required in contexts with high exploration and simultaneous exploitation demands, that is, ambidextrous social systems, supporting ambidextrous social relationships. 
High

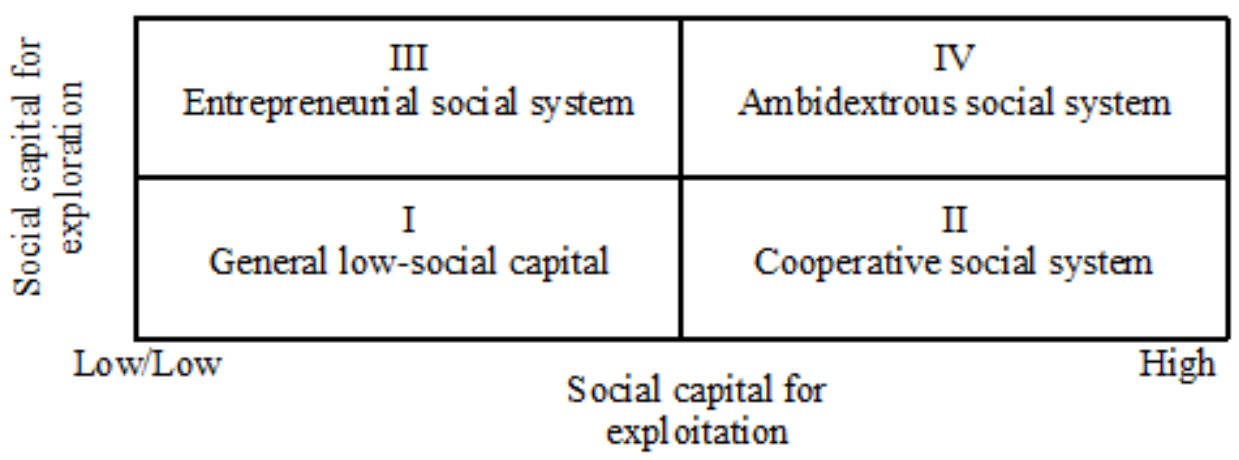

Figure 2. Social capital classification for exploration and/or exploitation activities

The organizational capital, which is the third dimension of intellectual capital, is related to the structures, procedures, norms, systems, routines, etc. that exhaustively store and preserve knowledge for subsequent use and application (Youndt, Subramaniam \& Snell, 2004). By its very nature, organizational capital tends to limit the ambidextrous capability of the company (Kostopoulos et al., 2015), since routines and standardized procedures and processes reduce flexibility, and therefore, reduce the autonomy to implement complex tasks such as the combination of exploration and exploitation. Having a certain organizational capital structure will condition the way in which employees work, organize, acquire, transmit and use knowledge within the firm. In this respect, Kang and Snell (2009) describe two competing ways of applying organizational capital: mechanistic and organic. The former presents formalized processes, structures and routines that facilitate the institutionalization of the extant knowledge, allow efficient coordination and the creation of certain frames of reference within which employees can act. By contrast, the latter shapes a more flexible context in which autonomy, opportunities and alternative perspectives and interpretation frames are key issues.

Nevertheless, there is an on-going debate in the literature with regards to how the mentioned types of organizational capital affect exploration and exploitation activities. Gilson, Mathieu, Shalley and Rudd (2005) and recently, Kang et al. (2012) discuss that mechanistic organizational capital may foster exploration because well-known and established routines, procedures and systems allow employees to have more time to spend on creating new knowledge or developing novel ideas. Even in organic organizational capital, some control structures provide sufficient stability for coordination and that preservea sufficient degree of flexibility for modification and improvisation (Eisenhardt \& Sull, 2001). 
These arguments could suggest that the organic organizational capital may support both exploration and exploitation.

Consequently, previous explanations lead us to consider the need for a particular organizational capital to allow companies to implement exploratory activities, while it also permits the development of efficient exploitative actions, and configuring the ambidextrous organizational capital (Figure 3).

\begin{tabular}{|c|c|c|}
\hline \multicolumn{3}{|c|}{ High } \\
\hline \multirow{2}{*}{ 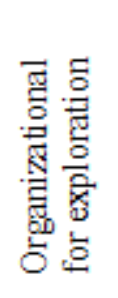 } & $\begin{array}{c}\text { III } \\
\text { Organic organizational capital }\end{array}$ & $\begin{array}{c}\text { IV } \\
\text { Ambidextrous organizational } \\
\text { capital }\end{array}$ \\
\hline & $\begin{array}{c}\text { I } \\
\text { Lack of infrastructure }\end{array}$ & $\begin{array}{c}\text { II } \\
\text { Mechanistic organizational } \\
\text { capital }\end{array}$ \\
\hline & $\begin{array}{r}\text { Organiza } \\
\text { ex }\end{array}$ & $\begin{array}{l}1 \text { capital for } \\
\text { ation }\end{array}$ \\
\hline
\end{tabular}

Figure 3. Organizational capital for exploration and/or exploitation activities 


\section{Leveraging human capital and ambidextrous intellectual capital emergence}

\subsection{Individual level: Creating ambidextrous human capital}

To deepen the processes from which ambidextrous capabilities arise, we integrate multilevel model arguments and intellectual capital assumptions, considering the different origins of ambidexterity through the organizational levels (Figure 4).

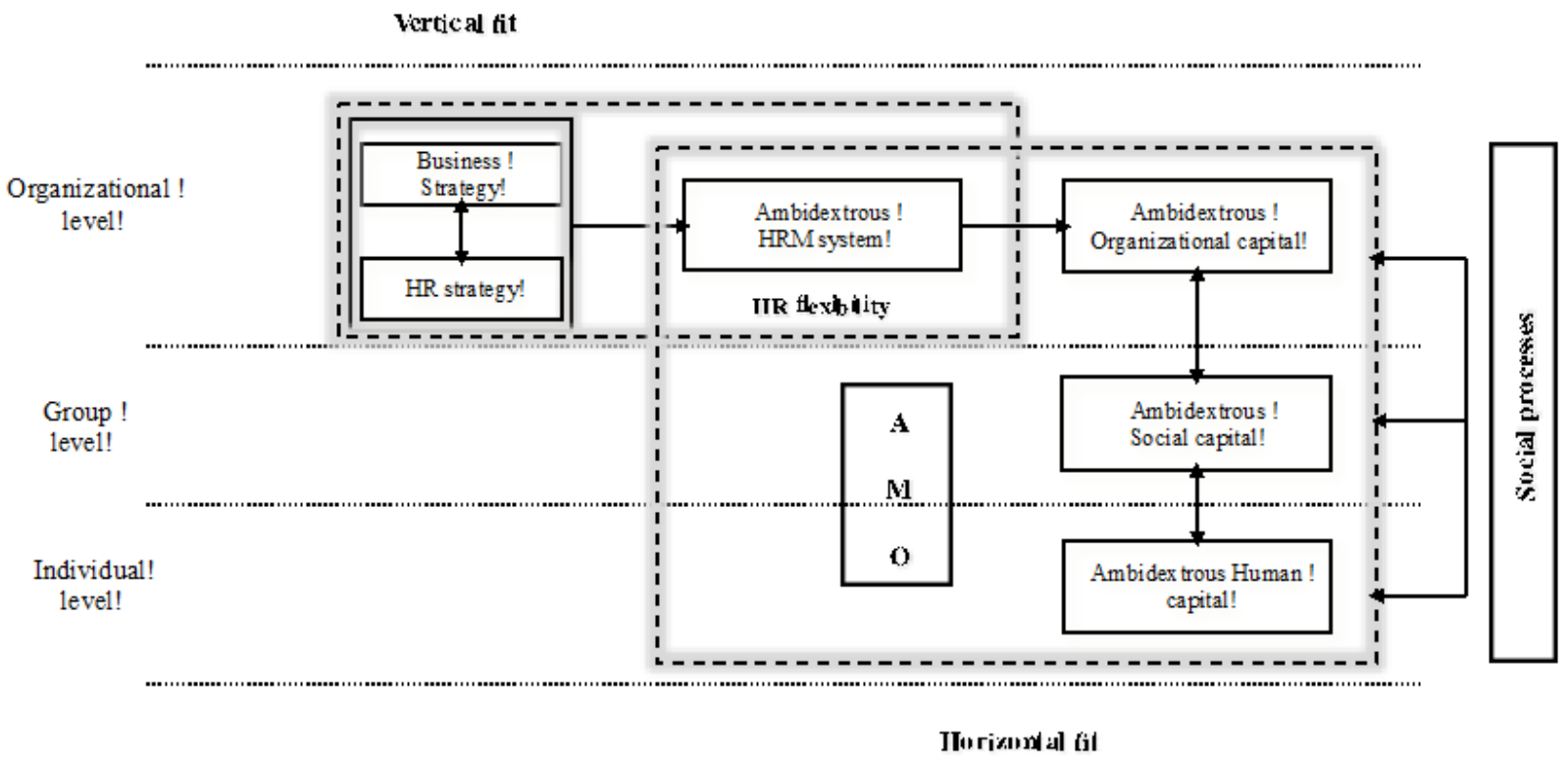

Figure 4. Multilevel model proposal

Starting from the individual level, the literature failsto explain how individuals' knowledge, skills and abilities (KSAs) exhibit across organizational levels and how they are linked to ambidextrous strategic capabilities (Jansen et al., 2012; Kostopoulos et al., 2015). In this sense, an alternative model to explain the leveraging of ambidextrous intellectual capital is required. To do so, we follow Ployhart and Moliterno (2011:128) in pointing out that 'the "collective" unit-level buman capital resource "originates" in individual-level employee $K S A s^{\prime}$.

According to previous definitions and implications, generating appropriate individual ambidextrous human capital becomes an extremely important first condition to finally obtain ambidextrous intellectual capital, as the former works as the pillar on which the latter is built. However, having a 
certain set of human capital attributes does not imply that identical competences appear in other organizational levels. As Kozlowski and Klein (2000) explain, complete isomorphism between levels is not common, but partially isomorphic cases normally manifest. These arguments lead us to consider the particular relevance of how organizations foster and manage individual ambidextrous capabilities before they are combined and amplified through organizational levels (Ployhart \& Moliterno, 2011). In this sense, we introduce Lepak et al.'s (2006) arguments based on the AMO Theory, explaining that HR systems can be oriented to directly influence individuals' abilities, motivation and opportunity to perform (Appelbaum et al., 2000). The logic of our argumentation posits that organizations need to engender proper ambidextrous human capital as the first step to finally achievingambidextrous intellectual capital. We, therefore, propose that ambidextrous human capital will be built on the basis of individual skills by implementing HRM subsystems with the specific objective of promoting employees' abilities, motivation and contextual opportunity to simultaneously deploy exploration and exploitation (Figure 4).

Thus, generalist human capital presents, by definition, the ambivalent knowledge, skills and abilities as being ambidextrous. However, having a certain human capital orientation is only a necessary but insufficient condition to ensure ambidextrous behaviours. In this sense, particular HR practices are required to improve and obtain employees' potential ambidexterity. Considering this, we propose that:

P1. HRM practices oriented towards improving ambidextrous knowledge, skills and abilities will enhance employees' capabilities, which develop exploitative and explorative activities.

Additionally, employees' motivation to perform in an ambidextrous way will be conditioned through the configuration of a proper climate, incentives and rewards. These actions will guide employees' behaviours towards building ambidextrous human capital since, similar to the previous reasoning, an employee may have sufficient capabilities, but the lack of motivation could hinder the efficient deployment of ambidextrous behaviours:

P2. HRM practices oriented to foster motivation to perform ambidextrously will improve employees' capabilities, which develop exploitative and explorative activities.

But, even if employees have the abilities and the motivation to develop ambidextrous individual competences, organizations should ensure an appropriate context and conditions in which to perform. Although there is a lack of consensus in the literature about what exactly 'opportunity' means, authors usually refer to it as the structure of work, the level of employee involvement, participation and empowerment (Lepak et al., 2006). In our case, 'opportunity', similarly to the other dimensions (abilities 
and motivation), will be focused on those practices to make easier the adoption of ambidextrous attitudes and behaviours.

P3. HRM practices oriented to foster opportunities for employees to deploy ambidextrous behaviours will improve employees' capabilities, which develop exploitative and explorative activities.

\subsection{Group level: The role of ambidextrous social capital}

Once organizations ensure an accurate stock of human capital at the individual level, these particular skills need to be amplified through employee interactions (Kozlowski \& Klein, 2000). In the ambidexterity context, individual social skills play a determinant role in facilitating knowledge exchange and the creation of ambidextrous capabilities. They ensure the first necessary condition for carrying out efficient social processes (Subramaniam \& Youndt, 2005).

To explain the process by which this occurs, we adapt Ployhart and Moliterno's (2011) multilevel model to the ambidexterity context. In doing so, we firstly define the two main and interrelated elements of the model: complexity of the task environment and social processes. Regarding the former, those authors explain that, drawing on teams literature, the collective phenomenon arises from the interaction between team members through which they coordinate to combine their knowledge, abilities and skills to solve problems and requirements. The latter refers to those social mechanisms helping the leveraging of the individual human capital. The linkages between dimensions of social capital—structural, affective and cognitive-will foster the abilities, motivation and opportunities of employees to better perform social relationships and knowledge exchange (Kang \& Snell, 2009).Applying these arguments to Ployhart and Moliterno's (2011) model, we provide a clarification of how social processes may work.

Task complexity and social capital are closely linked since more complex activities are expected to demand deeper collaboration than are easier tasks (Ployhart \& Moliterno, 2011). Generally, exploitation involves recurrent combinative mechanisms related to existing and familiar knowledge (March, 1991). It is a process that entails the crystallization of cause-effect relationships within a particular knowledge area and leads organizations to rely on prior success, looking for similar past solutions. By contrast, exploration implies new or emergent knowledge, configuring a volatile organizational reality in which the company expands its knowledge domains and looks for novel solutions. In this sense, exploitation will be more automatic because it is based on extant routines, norms and procedures. Therefore, as employees know how to behave and how their work should be done and organized, exploitation 
activities will present a relatively low level of complexity. Instead, exploration, because of its very nature, demands newer processes and combinative mechanisms that are normally new to employees. Exploration occurs in an uncertain context, where errors may appear because of the novel character of the tasks and processes. This leads us to consider a higher complexity in order to implement such exploratory activities. Therefore, the higher the task complexity, the greater the sophistication of social processes involved.

However, social capital cannot be studied without considering the specific characteristics of the individual human capital involved in such social processes, because they are 'inextricably tied' together (Subramaniam \& Youndt, 2005). Indeed, cooperative social systems will ensure the efficient development of tasks and activities because of the existence of robust and reliable networks in which a shared understanding of how knowledge should be combined is present. These characteristics allow specialists to improve their particular knowledge through closer contacts with other specialists within a similar area (Bunderson \& Sutcliffe, 2001; Kang et al., 2012). Nevertheless, these systems are also able to extract the explorative potential from the specialist human capital (Kang \& Snell, 2009). In fact, these social systems promote close personal interactions through their tight and strong social links so that employees can have access to diverse knowledge, thereby avoiding 'functional bias'. Moreover, the generalized trust of the cooperative social system reduces opportunistic behaviours such as retaining knowledge (Leana \& Van Buren, 1999), and the increasing number of contacts would foster shared understanding and common shaping of new knowledge. In doing so, specialists will have access to a wider range of information and quality resources (Mura, Radaelli, Spiller, Lettieri \& Longo, 2014), allowing them to look for novel issues. Along these lines, we propose that:

P4. Cooperative social systems will positively affect specialists' capacity to perform exploitation.

P5. Cooperative social systems will positively affect specialists' capacity to perform exploration.

By contrast, the above-mentioned social cooperative attributes normally hinder generalists' skills when implementing exploitative activities. This usually happens because of the rigidity derived from the 'relational inertia', which in some cases may generate overlapped and redundant knowledge (Coleman, 1988; Kang \& Snell, 2009). Therefore, we propose that:

P6. Cooperative social systems will negatively affect generalists' capacity to perform exploration.

However, generalists will benefit from entrepreneurial social systems that improve their contribution to the explorative activities. Generalists might be able to deploy both exploration and exploitation 
activities if they were supported by a proper social system, and generalists' task performance and human capital leveraging would then be improved. In this way, entrepreneurial systems offer a greater degree of flexibility, allowing different possibilities for contacts to acquire new knowledge from distinct areas. In fact, generalists are more capable of working within a dispersed and sporadic network of contacts, and make the most of their new contacts (Kang \& Snell, 2009). Furthermore, since generalists possess broader and more strategic knowledge, they tend to be better at sharing and combining diverse knowledge (Iansiti, 1993). Consequently:

\section{P7. Entrepreneurial social systems will positively affect generalists' capacity to perform exploration.}

Expanding Kang and Snell's (2009) arguments regarding the supplementary relationship between human capital typology and social systems, we argue that entrepreneurial social systems may, in some situations, improve specialists' capabilities to develop exploitative activities. In particular, sparse networks normally provide a proper context that allows employees to access novel and diverse knowledge creating links between employees and groups within and across firm boundaries (Kang, Morris \& Snell, 2007). However, these original assumptions do not consider the human capital orientation. In this respect, if specialist employees would interact in such a social system, it is possible that they would create sporadic relationships based on their 'functional experiences', instead of looking for novel knowledge (Dougherty, 1992). This would lead to small specialist groups being configured, building a suboptimal way of exploitation (Kang \& Snell, 2009). Consequently, although companies in this reality could not reach 'pure' exploitation processes, entrepreneurial social systems would extract the exploitative potential of specialists. Therefore:

\section{P8. Entrepreneurial social systems will positively affect specialists' capacity to perform exploitation.}

By combining both social systems, we observe that a cooperative system will underpin two functions in organizations:

- supporting exploitation because of its main attributes and,

- obtaining exploratory potential from specialists who, by definition, are less likely to deploy ambidextrous behaviours.

Similarly, entrepreneurial systems, apart from reinforcing specialist knowledge, will improve generalists' contributions to explorative actions. With this, depending on the nature of human capital, organizations would implement different social systems, resulting in either optimal or suboptimal ambidexterity, since being ambidextrous does not necessarily imply a balanced combination of 
exploration and exploitation, but just different combinations of them (Simsek, Heavey, Veiga \& Souder, 2009).

Cooperative systems support exploitation and may obtain exploratory potential from specialists who, by definition, are less likely to deploy ambidextrous competences. Similarly, entrepreneurial systems, apart from reinforcing specialist knowledge, could improve generalists' contributions to explorative actions. Depending on the nature of human capital, organizations would implement different social systems, resulting in either optimal or suboptimal ambidexterity. In light of the previous arguments, we identify different ways of achieving ambidextrous capabilities. On the one hand, there are optimal situations in which 'pure ambidexterity' is reached because the organization is composed of a majority of generalists. In this context, ambidextrous social systems that combine exploration and exploitation activities are needed. They would allow companies to develop a continuous process of exploration and exploitation instead of implementing them separated by time, generating and leveraging ambidextrous human capital across organizational levels.

On the other hand, suboptimal situations will be reached in the following cases (Table 2):

- Majority of specialists: Cooperative social systems could be implemented because they may improve specialists' capabilities for exploration (P5) and, predominantly for exploitation (P4). Due to the nature of this social system, in this case, we would find a predominance of exploitation.

- Majority of generalists: Another way to obtain a certain degree of ambidexterity is by applying entrepreneurial social systems to a majority of generalist employees. In this case, entrepreneurial social systems could be considered as the most appropriate option, since generalists are ambidextrous employees by nature, so that this social system would reinforce exploration (P7), while cooperative systems would hinder it (P6). In this way, exploration would be more predominant than exploitation because the social system would not have relevant effects on exploitation. Generalist employees will develop exploitation because they have skills and abilities to do so, ensuring a sufficient level to support exploration (Kostopoulos et al., 2015).

- Similar number of specialists and generalists: Implementing entrepreneurial social systems would cover both the exploration of generalist employees (P7) and the exploitation of specialists (P8), with a predominance of the former, because of the main characteristics of the 
social system. In this situation, ambidextrous capabilities would arise at group level, from the interaction between generalist and specialist employees.

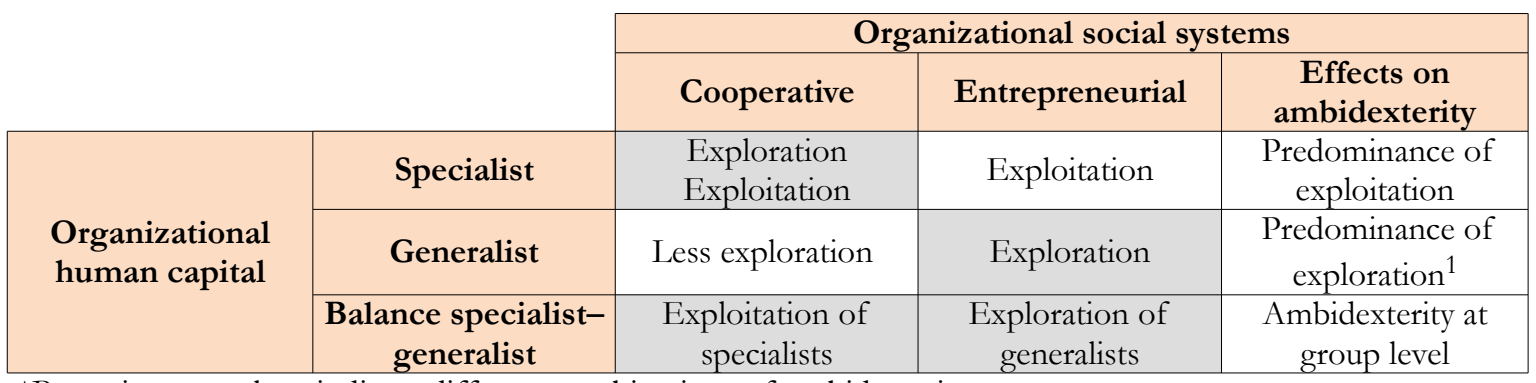

*Boxes in grey colour indicate different combinations of ambidexterity.

1. In this typology, generalists would develop exploitation by nature, because these employees have the abilities and skills needed to develop both activities.

Table 2. Suboptimal configurations for ambidexterity

This social context will help the company to reduce tensions between exploratory and exploitative actions, addressing one of the most controversial issues found in ambidexterity research (Lavie, Stettner \& Tushman, 2010).

\subsection{Macro-level perspective: Ambidextrous competences and organizational capital}

To give support to the previous social processes, the final part of the model is located at a macro level of study, showing the results of the ambidextrous human capital emergence process (Figure 4). Bontis (1998) posits that organizational capital is the way to measure intellectual capital at the organizational level. In other words, this perspective allows social capital episodes to be observed from a global point of view and indicates how ambidextrous human capital has been elevated and transformed so that it can help to build a source of competitive advantage-when it can be considered as valuable, rare, inimitable and supported by the organization -(Barney \& Wright, 1998). Nevertheless, this VRIO focus is not only related to the individual human capital, but it additionally considers the social dynamics included in the collective phenomenon. Being more specific, what is difficult to imitate is the integration of the employees' human capital, generalist or specialist, as the input of the emergence enabling process and the configuration of unique social interactions. This leads organizations to create strategic synergies between human and social capital (Subramaniam \& Youndt, 2005), to finally develop 
organizational core competences, in our case, ambidextrous competences. That is, it constitutes a continuous circle of exploration and exploitation.

All the described processes, from the individual to organizational levels, need to find support in a certain 'organizational infrastructure'. Organizational capital usually reduces the ability of companies to be ambidextrous because of the rigidity of extant routines and policies, the lack of cognitive diversity and, in general, the organizational inertia (Leonard-Button, 1992; Thornhill \& Amit, 2003; Kostopoulos et al., 2015). Hence, we propose that, rather than organizations possessing different organizational capital to develop exploration and exploitation as two disconnected blocks, a flexible and versatile organizational capital is required. In this vein, we understand that ambidextrous organizational capital will be the set of guides, principles and flexible routines and procedures that:

- admit some freedom for exploration (new ideas, novel knowledge exchange, fluent interactions, etc.), leading to what the literature recognizes as organizational improvisation (Orlikowski, 2002) and,

- ensure a certain level of control to take advantage of efficient exploitative activities.

Moreover, the organizational capital gains greater importance because it reflects the materialization of synergistic and unique combinations, among others, of ambidextrous human and social capital, configuring routines, systems, etc. that remain in the company. If organizations were not able to create sufficient organizational capital, core employees would go, taking their strategic human and social capital with them. In that situation, core employees' retention would play a crucial role inthe retention of ambidextrous competences (Ordoñez-de Pablos \& Parreño-Fernández, 2012).

However, as discussed above, the literature still remains unclear regarding the effect of mechanistic and organic organizational capital effects on exploration and exploitation (Jansen, van den Bosch \& Volberda, 2006). On the one hand, there are some arguments explaining that mechanistic organizational capital supports exploitation and hinders exploration and vice versa (Kang \& Snell, 2009). On the other hand, several authors point out that mechanistic organizational capital may have the potential to support both exploration and exploitation (Gilson et al., 2005; Kang et al., 2012). Therefore, in such a contradictory context, instead of considering two different orientations of organizational capital to support either exploration or exploitation, we propose a wider organizational capital that provides the company with a specific organizational 'infrastructure' for the ambidextrous context. Drawing on the above discussion, the next proposition is: 
P9. The ambidextrous organizational capital will positively influence the development of exploitative and explorative activities in a concurrent manner.

\section{Conclusions, limitations and future research lines}

Obtaining ambidextrous capabilities is a notably complex process comprising different strategic elements. Diverse calls in the literature have demanded that more attention be paid to the specific strategic processes and mechanisms involved in ambidexterity (Kang \& Snell, 2009; Kostopoulos et al., 2015). With our proposed model, we offer an alternative and systematic way to explain how individual human capital is leveraged so that synergies between different HRM subsystems at diverse organizational levels appear, achieving ambidextrous intellectual capital. It contributes to the extant literature by clarifying how this process works, through the introduction and description of the intellectual capital dimensions in the ambidexterity context. It also establishes some principles -HR horizontal fit and HR flexibility- as crucial requirements for the process to succeed. These conditions, widely discussed in the SHRM literature, are especially relevant in ambidextrous and multilevel research studies.

In building the theoretical model, our paper contributes to the previous literature by considering ambidexterity as a two independent and complementary processes (Burgelman, 2002); this approach conditions the nature of our model. In this vein, by integrating arguments from the literature on intellectual capital, SHRM and multilevel applicability, we propose a model that advances the previous literature in three ways:

- Our discussion about the elements of intellectual capital provides us with the input (human capital), mechanisms (social capital) and the infrastructure (organizational capital) to generate ambidextrous competences.

- The multilevel perspective reveals the context in which ambidexterity is possible by developing exploration and exploitation activities in a concurrent manner.

- The SHRM literature provides the model with the required tools to engage distinct mechanisms involved in the process, and the necessary conditions for this to occur (HR flexibility and horizontal fit). 
Those perspectives, individually considered, only explain part of the ambidexterity phenomenon. By considering them together we reach diverse and interesting conclusions. Generally speaking, the mechanisms to generate ambidexterity in the proposed model can be a source of competitive advantage considering the actual and potential human, social and organizational capital of the company. In this sense, HR policies and practices need to be designed on the basis of the extant intellectual capital and to develop potential ambidextrous competences, looking for positive synergies between different dimensions (Yang \& Lin, 2009; Hansen, Güttel \& Swart, 2017). In doing so, firms have to build consistent HRM systems to develop ambidextrous skills at individual, group and organizational levels. Then, HR policies and practices will facilitate the knowledge exchange process (Ordoñez-de Pablos \& Parreño-Fernández, 2012).

Regarding the ambidextrous human capital, the paper concludes that although the generalist human capital is ambidextrous by nature, specialist employees can also be a source of ambidexterity. As discussed, using the proper social mechanisms, organizations can optimize the ambidextrous contributions of generalist workers while also fostering and extracting value from specialist human capital profiles (Kang \& Snell, 2009). Further, we explore particular 'suboptimal' ways to create ambidexterity by explaining how social systems (cooperative and entrepreneurial) may influence specialists' and generalists' abilities to be ambidextrous. This reasoning assumes that being ambidextrous does not necessarily imply having a perfect balance between exploration and exploitation. Differing degrees of both activities may also help to build specific levels of ambidexterity.

Two relevant conclusions arise from this argument:

- there is a crucial connection between human capital and social capital and,

- ambidextrous competences can be reached through different paths.

In relation to the first aspect, the theoretical discussion describes a two-way relationship between these two intellectual capital dimensions. This leads us to conclude that ambidextrous human capital relies heavily on employees' social skills. It could be argued that higher levels of individual social skills would make the efficient functioning of social processes and mechanisms easier. On the other hand, particular orientations of social capital processes will condition ambidexterity at the individual human capital level (cooperative and entrepreneurial systems).

Regarding the second concern, despite it not being the focus of the present study, we also conclude that ambidextrous competences may stream from different sources, depending on the human and social 
capital attributes and supporting the idea that ambidexterity should be examined at different strategic levels (Gupta et al., 2006):

- Ambidextrous employees at the individual level will establish ambidextrous groups, resulting in ambidextrous organizations;

- Separated exploratory employees and exploitative employees working together can build ambidextrous groups, leading to ambidextrous organizations;

- The conjunction of exploratory and exploitative groups will also result in ambidextrous organizations.

This second issue reinforces our argument on the bidirectional relationship between ambidextrous human and social capital. In fact, due to the complexity and the importance of these interactions in the emergence of ambidextrous intellectual capital, we suggest that more research is also required in this area; this will be addressed in future studies.

Additionally, when discussing the organizational capital, we also deduce that, more than having two 'organizational infrastructures' to support either exploration or exploitation, only one is needed if it comprises elements and procedures that provide sufficiently high levels of organizational flexibility to promote exploration, and enough control mechanisms to maintain exploitation. The presence of two alternative types of organizational capital may cause certain levels of rigidity and coordination problems, hindering the emergence of ambidextrous competences.

As observed, the convergence of different subsystems managing the intellectual capital dimensions is one of the principal issues in the ambidexterity context (Hansen et al., 2017). Further, a high degree of HR practices adaptability to better achieve those ambidextrous human, social and certain organizational $\mathrm{f}$ capital is inexorably demanded. Following on from this, to complete the proposed model, we also introduce two necessary and connected conditions (Wright \& Snell, 1998; Ketkar \& Sett, 2009) to make the processes of leveraging human capital and ambidexterity emergence possible, that is, the HR flexibility and the HR horizontal fit.

Traditionally, the SHRM literature has widely recognized the relevance of fulfilling two main conditions so that HRM systems and practices can contribute to organizational success as regards horizontal and vertical fit (Martín-Alcázar, Romero-Fernández \& Sánchez-Gardey, 2005; Samnani \& Singh, 2013). Considering these arguments, implicit in the proposed model, there are three different HRM 
subsystems with specific objectives (Lepak et al., 2006), one for each intellectual capital dimension (Figure 4):

- the buman capital subsystem, where the objective is to foster and generate individual ambidextrous human capital,

- the social capital subsystem, where the main aim is to create the appropriate base on which relationships between employees act as main mechanisms to leverage individual human capital and create ambidextrous intellectual capital and,

- the subsystem related to the organizational capital, as these are tools that companies have to provide the required infrastructure, giving support to the generation and storage of ambidextrous intellectual capital.

Similarly, we pay attention to the horizontal fit in the described multilevel model. For example, when designing HR practices to stimulate ambidextrous individual knowledge, skills and abilities, organizations should consider the development of social skills. As mentioned in previous sections, to properly implement social capital practices so that individual human capital can be transformed across different organizational levels, a necessary condition is for employees to possess a suitable set of communicative and social skills. As a consequence, spending resources on acquiring social skills will provide the company with the desired behaviours and conduits for their workers to transmit and share knowledge (Subramaniam \& Youndt, 2005). These HR practices will be configured from the perspective of social capital practices, with the objective of creating synergies and ensuring that social capital will be well developed on the basis of proper human capital skills and vice versa.

However, in the ambidexterity context, HR flexibility also plays a crucial role. Based on Wright and Snell's (1998) logic, Ketkar and Sett (2009) state that no kind of flexibility can be achieved without the proper blend of HR practices whose objective is to promote such flexibility. These authors introduce in the HR flexibility construct a new dimension—the flexibility-inducing HR practices_configuring a particular ambidextrous HRM system (Gibson \& Birkinshaw, 2004; Ketkar \& Sett, 2009), including human capital, social capital and organizational capital subsystems, and whose strategic aim is creating and managing ambidextrous organizational competences. In this way, HR horizontal fit and HR flexibility can be achieved simultaneously, ensuring the proper environment for the human capital leveraging processes and the subsequent creation of ambidextrous competences. This logic leads us to consider that both HR horizontal fit and HR flexibility are closely related, because the former can be understood as a static condition whereas the latter is seen as a continuous competence of the organization (Wright 
\& Snell, 1998). It can thus be argued that HR flexibility complements the potential rigidity of the fit, allowing a multifaceted HR system to develop.

Additionally, one of the most important professional implications of the present research is focused on those prescriptions to help managers build ambidextrous capabilities in current companies. Applying a configurational point of view, HR managers may focus on designing policies and practices for each intellectual capital dimension. For example, practices oriented to attract ambidextrous employees may be linked to the extensive external and internal recruitment. Additionally, at group level, to generate ambidextrous social capital, HR managers should foster collaboration between different employees and organizational units through work group to develop complex tasks, promoting interactions to create knowledge networks or implementing feedback programs to improve knowledge exchange between employees. Finally, organizational ambidextrous capital may be created through an efficient documentation process. In doing so, HR managers should implement specific practices to register and update knowledge using reports, database, archives, manuals, etc. As a result, explorative and exploitative knowledge can be integrated to build ambidextrous capabilities.

Finally, the following limitations should be borne in mind when considering the conclusions of our theoretical discussion. This study proposes a broad framework to explain how individual ambidextrous human capital may be leveraged and transformed by social processes across different organizational levels to finally achieve ambidextrous intellectual capital. However, this wide perspective does not allow us to specify main social and fit mechanisms to ensure that the intricate leveraging process is completely resolved. In this sense, we suggest different lines for future research focused on deepening some of the aforementioned concerns:

- going into detail about specific social processes as main mechanisms in multilevel models, determining how they work and how they should be managed (Subramaniam \& Youndt, 2005);

- explaining in more detail the consequences for the leveraging processes of different combinations of intellectual human capital dimensions (Kang \& Snell, 2009);

- specifying the main elements, policies and practices that comprise the ambidextrous HRM system (Turner et al., 2015) and,

- examining how HR flexibility and HR horizontal fit work simultaneously and how they can be jointly developed. 


\section{Acknowledgments}

The authors appear in alphabetical order and have contributed equally to this paper. The research project described in this paper was developed under the Research Group SEJ-449 funded by the Andalusian Government (Andalusian Plan for R\&D\&I 2007-2013) and the Research Projects ECO2011- 26982 and ECO2014-56580-R, funded by the Spanish Ministry for Science and Technology (Non-oriented Fundamental Research Projects Subprogram).

\section{References}

Appelbaum, E., Bailey, T., Berg, P., \& Kalleberg, A. (2000). Manufacturing competitive advantage: The effects of high performance work systems on plant performance and company outcomes. Ithaca, NY: Cornell University Press.

Barney, J. B., \& Wright, P. M. (1998). On becoming a strategic partner: The role of human resources in gaining competitive advantage. Human Resource Management, 37(1), 31-46. https://doi.org/10.1002/ (SICI)1099-050X(199821)37:1<31::AID-HRM4>3.0.CO;2-W

Bontis, N. (1998). Intellectual capital: An exploratory study that develops measures and models. Management Decision, 36(2), 63-76. https://doi.org/10.1108/00251749810204142

Bunderson, J.S., \& Sutcliffe, K.M. (2001). Comparing alternative conceptualizations of functional diversity in management teams: Process and performance effects. Academy of Management Journal, 45(5), 875-893. https://doi.org/10.2307/3069319

Burgelman, R.A. (2002). Strategy as vector and the inertia of Coevolutionary lock-in. Administrative Science Quarterly, 47(2), 325. https://doi.org/10.2307/3094808

Coleman, J.S. (1988). Social capital in the creation of human capital. American Journal of Sociology, 94(s1), S95. https://doi.org/10.1086/228943

Delery, J.E. (1998). Issues of fit in strategic human resource management: Implications for research. Human Resource Management Review, 8(3), 289-309. https://doi.org/10.1016/S1053-4822(98)90006-7

Dougherty, D. (1992). Interpretive barriers to successful product innovation in large firms. Organization Science, 3(2), 179-202. https://doi.org/10.1287/orsc.3.2.179

Eisenhardt, K.M., \& Sull, D.N. (2001). Strategy as simple rules. Harvard Business Review, 79(1), 106-119. 
Gibson, C.B., \& Birkinshaw, J. (2004). The antecedents, consequences, and mediating role of organizational ambidexterity’. Academy of Management Journal, 47(2), 209-226. https://doi.org/10.2307/20159573

Gilson, L.L., Mathieu, J.E., Shalley, C.E., \& Ruddy, T.M. (2005). Creativity and standardization: complementary or conflicting drivers of team effectiveness. Academy of Management Journal, 48(3), 521-531. https://doi.org/10.5465/AMJ.2005.17407916

Gupta, A.K., Smith, K.G., \& Shalley, C.E. (2006). The interplay between exploration and exploitation. Academy of Management Journal, 49(4), 693-706. https://doi.org/10.5465/AMJ.2006.22083026

Hansen, N.K., Güttel, W.H., \& Swart, J. (2017). HRM in dynamic environments: Exploitative, exploratory, and ambidextrous HR architectures. Manuscript submitted for publication. https://doi.org/10.1080/09585192.2016.1270985

Iansiti, M. (1993). Real-world R\&D: Jumping the product generation gap. Harvard Business Review, 71(3), 138-147.

Jansen, J.J.P., Simsek, Z., \& Cao, Q. (2012). Ambidexterity and performance in multiunit contexts: Cross-level moderating effects of structural and resource attributes. Strategic Management Journal, 33(11), 1286-1303. https://doi.org/10.1002/smj.1977

Jansen, J.J.P., van den Bosch, F.A.J., \& Volberda, H.W. (2006). Exploratory innovation, exploitative innovation, and performance: Effects of organizational antecedents and environmental moderators. Management Science, 52(11), 1661-1674. https://doi.org/10.1287/mnsc.1060.0576

Kang, S.-C., Morris, S.S., \& Snell, S.A. (2007). Relational archetypes, organizational learning, and value creation: Extending the human resource architecture. Academy of Management Review, 32(1), 236-256. https://doi.org/10.5465/AMR.2007.23464060

Kang, S.-C., \& Snell, S.A. (2009). Intellectual capital architectures and ambidextrous learning: A framework for human resource management. Journal of Management Studies, 46(1), 65-92. https://doi.org/10.1111/j.1467-6486.2008.00776.x

Kang, S.-C., Snell, S.A., \& Swart, J. (2012). Options-based HRM, intellectual capital, and exploratory and exploitative learning in law firms' practice groups. Human Resource Management, 51(4), 461-485. https://doi.org/10.1002/hrm.21484

Ketkar, S. \& Sett, P.K. (2009). HR flexibility and firm performance: Analysis of a multi-level causal model. The International Journal of Human Resource Management, 20(5), 1009-1038. 
Kostopoulos, K.C., Bozionelos, N., \& Syrigos, E. (2015). Ambidexterity and unit performance: Intellectual capital antecedents and cross-level moderating effects of human resource practices. Human Resource Management, 54(S1), s111-s132. https://doi.org/10.1002/hrm.21705

Kozlowski, S.W.J., \& Klein, K.J. (2000). A multilevel approach to theory and research in organizations: Contextual, temporal, and emergent processes. In K.J. Klein \& S.W.J. Kozlowski (Eds), Multilevel theory, research, and methods in organizations: Foundations, extensions, and new directions (pp. 3-90). San Francisco, CA: Jossey-Bass.

Laureiro-Martínez, D., Brusoni, S., Canessa, N., \& Zollo, M. (2015). Understanding the explorationexploitation dilemma: An fMRI study of attention control and decision-making performance. Strategic Management Journal, 36(3), 319-338. https://doi.org/10.1002/smj.2221

Lavie, D., Stettner, U., \& Tushman, M.L. (2010). Exploration and exploitation within and across organizations. The Academy of Management Annals, 4(1), 109-155. https://doi.org/10.1080/19416521003691287

Leana, C.R., \& van Buren, H.J. (1999). Organizational social capital and employment practices. The Academy of Management Review, 24(3), 538-555. https://doi.org/10.2307/259141

Leonard-Barton, D. (1992). Core capabilities and core rigidities: A paradox in managing new product development. Long Range Planning, 26(1), 111-125. https://doi.org/10.1016/0024-6301(93)90313-5

Lepak, D.P., Liao, H., Chung, Y., \& Harden, E.E. (2006). A conceptual review of human resource management systems in strategic human resource management research. Research in Personnel and Human Resources Management, 25(1), 217-271. https://doi.org/10.1016/S0742-7301(06)25006-0

March, J.G. (1991). Exploration and exploitation in organizational learning. Organization Science, 2(1), 71-87.https://doi.org/10.1287/orsc.2.1.71

Martín-Alcázar, F., Romero-Fernández, P.M., \& Sánchez-Gardey, G. (2005). Strategic human resource management: Integrating the universalistic, contingent, configurational and contextual perspectives. The International Journal of Human Resource Management, 16(5), 633-659. https://doi.org/10.1080/09585190500082519

Mura, M., Radaelli, G., Spiller, N., Lettieri, E., \& Longo, M. (2014). The effect of social capital on exploration and exploitation. Journal of Intellectual Capital, 15(3), 430-450. https://doi.org/10.1108/JIC-052014-0057

Nahapiet, J., \& Ghoshal, S. (1998). Social capital, intellectual capital, and the organizational advantage. Academy of management review, 23(2), 242-266. 
Ordoñez-de Pablos, P., \& Parreño-Fernández, J. (2012). Hacia una conceptualización del conocimiento de la empresa: un análisis ontológico. Revista Icade. Revista de las Facultades de Derecho y Ciencias Económicas y Empresariales, 72, 31-47.

Orlikowski, W.J. (2002). Knowing in practice: Enacting a collective capability in distributed organizing'. Organization Science, 13(3), 249-273. https://doi.org/10.1287/orsc.13.3.249.2776

Papachroni, A., Heracleous, L., \& Paroutis, S. (2014). Organizational ambidexterity through the lens of paradox theory: Building a novel research agenda. The Journal of Applied Behavioral Science, 51(1), 71-93. https://doi.org/10.1177/0021886314553101

Ployhart, R.E., \& Moliterno, T.P. (2011). Emergence of the human capital resource: A multilevel model. Academy of Management Review, 36(1), 127-150. https://doi.org/10.5465/amr.2009.0318

Samnani, A.-K. \& Singh, P. (2013). Exploring the fit perspective: An ethnographic approach. Human Resource Management, 52(1), 123-144. https://doi.org/10.1002/hrm.21516

Shane, S. (2000). Prior knowledge and the discovery of entrepreneurial opportunities. Organization Science, 11(4), 448-469. https://doi.org/10.1287/orsc.11.4.448.14602

Simsek, Z., Heavey, C., Veiga, J.F., \& Souder, D. (2009). A typology for aligning organizational ambidexterity's conceptualizations, antecedents, and outcomes. Journal of Management Studies, 46(5), 864-894. https://doi.org/10.1111/j.1467-6486.2009.00841.x

Subramaniam, M., \& Youndt, M.A. (2005). The influence of intellectual capital on the types of innovative capabilities. Academy of Management Journal, 48(3), 450-463. https://doi.org/10.5465/AMJ.2005.17407911

Thornhill, S., \& Amit, R. (2003). Learning about failure: Bankruptcy, firm age, and the resource-based view. Organization Science, 14(5), 497-509. https://doi.org/10.1287/orsc.14.5.497.16761

Turner, N., Maylor, H., \& Swart, J. (2015). Ambidexterity in projects: An intellectual capital perspective. International Journal of Project Management, 33(1), 177-188. https://doi.org/10.1016/j.jiproman.2014.05.002

Wright, P.M., \& Snell, S.A. (1998). Toward a unifying framework for exploring fit and flexibility in strategic human resource management. The Academy of Management Review, 23(4), 756. https://doi.org/10.2307/259061

Yang, C.-C. \& Lin, C.Y.-Y. (2009). Does intellectual capital mediate the relationship between HRM and organizational performance? Perspective of a healthcare industry in Taiwan. The International Journal of Human Resource Management, 20(9), 1965-1984. https://doi.org/10.1080/09585190903142415 
Youndt, M.A., Subramaniam, M., \& Snell, S.A. (2004). Intellectual capital profiles: An examination of investments and Returns. Journal of Management Studies, 41(2), 335-361. https://doi.org/10.1111/j.14676486.2004.00435.x

Intangible Capital, 2017 (www.intangiblecapital.org)

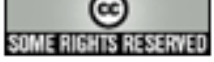

Article's contents are provided on an Attribution-Non Commercial 3.0 Creative commons license. Readers are allowed to copy, distribute and communicate article's contents, provided the author's and Intangible Capital's names are included. It must not be used for commercial purposes. To see the complete license contents, please visit http://creativecommons.org/licenses/by-nc/3.0/. 